\title{
A mui leal e heroica: fiscalidade e a Alfândega do Rio de Janeiro no pós-Restauração (1640-1668)
}

\author{
La muy leal y heroica: fiscalidad y la Aduana de Río de Janeiro en la \\ post-Restauración (1640-1668)
}

\section{The very loyal and heroic: taxation and the Customs of Rio de Janeiro in the post-Restoration (1640-1668)}

\author{
Helena de Cassia Trindade de Sá \\ Universidade Federal do Estado do Rio de Janeiro \\ helenatrindade@globo.com
}

Fecha de recepción: 22 de noviembre de 2017

Fecha de aprobación: 23 de febrero de 2018

\begin{abstract}
Resumo
Durante sessenta anos (1580 - 1640), Portugal e seus demais territórios estiveram na órbita da monarquia hispânica. Entretanto, o crescente descontentamento com o governo dos reis espanhóis deu força ao movimento pela Restauração do trono português, que chegou ao ápice com a aclamação do Duque de Bragança como D. João IV, rei de Portugal e Algarves. É nesse contexto de mudanças, marcado pela reorganização da exploração econômica no ultramar e constituição do sistema colonial, que buscaremos analisar a fiscalidade e a Alfândega do Rio de Janeiro.
\end{abstract}

Palavras-chave: Restauração, fiscalidade, Alfândega.

\begin{abstract}
During sixty years (1580 - 1640), Portugal and its territories were in the orbit of the Hispanic monarchy. However, the growing discontent with the government of the Spanish kings gave strength to the movement for the Restoration of the Portuguese throne, which reached its peak with the acclamation of the Duke of Braganza as D. João IV, king of Portugal and the Algarves. It is in this context of changes, marked by the reorganization of the economic exploitation in the overseas and constitution of the colonial system that we will try to analyze the taxation and the Customs of Rio de Janeiro.
\end{abstract}

Keywords: Restoration, taxation, Customs. 


\section{Um breve balanço historiográfico}

Alguns historiadores em diferentes épocas, por diversas trajetórias e partindo de uma pluralidade de pressupostos, colaboraram para a análise da fiscalidade no período colonial. Dessa forma, procuramos fazer um exame das produções historiográficas que tiveram esse tema como centro de suas análises.

$\mathrm{Na}$ interpretação de Luciano Figueiredo, a "fiscalidade executada na América portuguesa constituiu um dos principais fundamentos da política colonizadora". Ainda de acordo com o autor, "onde houvesse alguma forma de vida econômica os direitos do rei eram lembrados". Dessa forma, "a Fazenda Real e seus agentes colhiam, onde existisse, a riqueza que a empresa colonial proporcionava"'.

Para Angelo Carrara, a fiscalidade é um dos elementos principais, se não o mais importante, na relação entre uma metrópole e suas colônias, na medida em que através dos rendimentos extraídos, seja do comércio ou da exploração de metais preciosos, é possível suprir as despesas públicas e ainda promover a transferência da renda colonial para a metrópole. Considera também que, apesar de todos os esforços da Coroa, alguns temas como licitações fraudulentas, subornos, sonegação de impostos, improbidade administrativa, conluios e corrupção marcaram a fiscalidade do século XVII².

Já no tocante ao período pós-Restauração, Marcos Guimarães Sanches afirma que "as políticas coloniais se caracterizaram por um esforço fiscal capaz de fazer frente às prementes necessidades do Reino"3.

Já Luiz Antônio Silva Araújo diz que a guerra com a Espanha (1640-1668) foi um elemento decisivo no processo de mudança na fiscalidade régia, "trazendo uma participação mais decisiva das Câmaras municipais na fiscalidade no seiscentos" "4. Tal conjuntura flexibilizava as práticas fiscais ao vincular os tributos, que somente podiam ser criados com ordem régia, as chamadas edilidades, favorecendo a participação dos poderes locais nessa questão sem, contudo, comprometer o processo de afirmação da nova dinastia nas terras do ultramar ${ }^{5}$.

Pablo Oller Montserrat chama a atenção para um detalhe do período pós-Restauração em relação à fiscalidade: a contradição entre a rejeição em relação à alta carga

1 Luciano Raposo de Almeida Figueiredo, "Revoltas, fiscalidade e identidade colonial na América portuguesa: Rio de Janeiro, Bahia e Minas Gerais, 1640-1761" (Tese de Doutorado, Universidade de São Paulo, 1996), 6.

2 Angelo Alves Carrara. Receitas e despesas da Real Fazenda no Brasil. (Juiz de Fora: Editora UFRJ, 2009), 5-9.

3 Marcos Sanches. "Fiscalidade e fomento na colonização do Brasil: orientações e contradições". Anais. XVIII Simpósio Nacional de História (Londrina: ANPUH, 2005), 1.

4 Luiz Antônio Silva Araujo. "Contratos, comércio e fiscalidade na América portuguesa (1641-1730)" em Guerra e fiscalidade na Ibero-América colonial (séculos XVII-XIX). Coords. Ángelo Carrara et. Al. (Juiz De Fora: Ed UFJF, 2012).

5 Araujo. Contratos... 
tributária, fato que motivou o descontentamento que culminou com movimento que pôs fim à União Ibérica, e a necessidade urgente de se instituir novos tributos para angariar recursos para fazer frente aos elevados gastos com a defesa da colônia que vinham em escalada crescente ${ }^{6}$.

Visando suprir a lacuna existente a respeito da extração fiscal do comércio intercolonial é que realizamos a pesquisa sobre a aduana fluminense ${ }^{7}$ no período compreendido entre o inicio da União Ibérica até o fim da Guerra da Restauração. A investigação procurou demonstrar como foi estabelecido o posto alfandegário na cidade do Rio de Janeiro, identificando e analisando indícios da sua estrutura e dinâmica, sem deixar de lado a disputa pela ocupação dos seus cargos e os conflitos entre os oficiais aduaneiros e representantes dos outros poderes locais ${ }^{8}$.

Nossa pretensão com este artigo é traçar um panorama a respeito do papel da Alfândega no período pós-Restauração e ainda apontar em que medida a reorganização da atividade fiscal contribuiu para o funcionamento da empresa colonizadora.

\section{O pós-Restauração}

O crescente descontentamento de alguns setores sociais com o governo dos reis espanhóis durante a União Ibérica deu força ao movimento pela Restauração do trono português, que chegou ao seu ápice em 1640. A situação foi agravada entre a segunda e a terceira década do Seiscentos, sobretudo a partir das medidas implementadas pelo Conde Duque de Olivares, valido de D. Filipe IV, 9 que foram gradativamente minando o estabelecido pelo Estatuto de Tomar. Essas medidas compreendiam: concessões de mercês e ofícios a pessoas não naturais do Reino, a outorga do Vice-Reinado a estrangeiros ${ }^{10}$, e o aumento excessivo de impostos.

6 Mont Serrat, Pablo Oller. "O império português no Atlântico: poderio, ajuste e exploração (16401802)". (Tese de Doutorado, Universidade de São Paulo, 2013), 204.

7 Angelo Carrara e Luiz Antonio Silva Araújo mencionaram a Bahia em seus trabalhos. Recente dissertação de Helena Trindade de Sá (2016) procura suprir a lacuna que existia a respeito da instituição alfandegaria na capitania do Rio de Janeiro no período compreendido entre 1580 e 1668. "A Alfândega do Rio de Janeiro: da União Ibérica ao fim da Guerra da Restauração (ca.1580-ca.1668)". (Dissertação de Mestrado, Universidade Federal do Estado do Rio de Janeiro, 2016).

8 Sá, “A Alfândega....".

9 De acordo com José Antonio Escudero: “[...] el siglo XVII el gobierno por validos se converte em uma realidade institucional permanente. José Antonio Escudero. El Rey: História de la monarquia v. 1. (Barcelona: Planeta, 2008) 337. Ainda de acordo com o autor, com o acesso de Filipe IV ao trono, Olivares surge na cena política. Este "era um amigo y confidente como gentilhombre suyo, del príncipe Felipe antes de ser rey. Escudero, El rey..., 342. Da mesma forma, Maria Fernanda Bicalho citando Jean Fréderic Schaub diz que: $\mathrm{O}$ valido posiciona-se como intermediário entre o rei e o reino. A sua autoridade depende da boa vontade do príncipe e torna-se central no dispositivo governamental, na medida em que apenas o valido, juntamente com o rei, se encontra em posição de presidir às consultas do conjunto dos Conselhos da Monarquia. Maria Fernanda Bicalho. "As tramas da política: política, conselhos, secretários e juntas na administração da monarquia portuguesa e seus domínios ultramarinos". Na trama das redes: política e negócios no império português, séculos XVI-XVIII. João Fragoso et. Al. (Rio de Janeiro: Civilização Brasileira, 2010)

10 Maria Luísa Marques da Gama, "O Conselho de Estado no Portugal Restaurado: teorização orgânica 
Devemos considerar que também contribuíram para a revolta o desrespeito com os foros, os privilégios e as liberdades ${ }^{11}$ e o esquecimento do Conselho de Portugal, tais quais outras instituições lusitanas típicas do governo polissinodal, que foram pouco a pouco perdendo importância em nome da agilização do processo decisório ${ }^{12}$.

Além desses fatores, a tomada de Angola pelos holandeses e a insegurança da navegação através do Oceano Atlântico, juntamente com a conquista das principais possessões portuguesas do oriente pelos ingleses e batavos, assim como uma parte do nordeste do Brasil, também são condicionantes que geraram grande insatisfação e que podem ser somados aos demais ${ }^{13}$. O sebastianismo e o nacionalismo vivos nas tradições populares e nas obras intelectuais davam argumentos espirituais ao clima de contestação ${ }^{14}$.

Dessa forma, os sacrifícios impostos a Portugal e a seu império atlântico fizeram lançar um movimento separatista, organizado pelos letrados e por uma parcela da nobreza até então sem expressão política, e que via nessa iniciativa uma oportunidade de ampliação de seu poder de barganha ${ }^{15}$. Esse grupo, embora tenha recebido o apoio do povo, não contou com a sua participação no golpe palaciano que restaurou o trono na forma anterior à união com a Coroa hispânica ${ }^{16}$.

Após a aclamação do Duque de Bragança como D. João IV, fez-se necessário trabalhar pelo reconhecimento da independência nos outros reinos estrangeiros e ainda na Santa Sé, que se manteve ao lado dos reis espanhóis até o fim da guerra da Restauração. A rigor, o novo rei não promoveu alterações significativas à estrutura administrativa portuguesa, mantendo ainda os órgãos do governo constituídos pelos representantes oriundos da administração filipina. Preservou os quadros de pessoal assim como as leis e as instituições do período dos Habsburgo ${ }^{17}$, a fim de se "evitar o caos, bem como angariar simpatias e lealdades" $" 18$. Dedicou-se a resolver os problemas

e o exercício do poder político na corte Brigantina (1640-1706)" Dissertação de Mestrado, Universidade de Lisboa, 2011), 77.

11 Eduardo D’Oliveira França, Portugal na época da Restauração, (São Paulo: HUCITEC, 1997), 273.

12 Gama, "O Conselho...", 77.

13 Vitorino Magalhães Godihno, Ensaios II: sobre a História de Portugal, (Lisboa: Livraria Sá da Costa Editora, 1978), 399.

14 França, Portugal..., 77-78.

15 Edval de Souza Barros. "Negócios de tanta importância: o Conselho Ultramarino e a disputa pela condução da guerra no Atlântico e no Índico (1643-1661)". (Tese de Doutorado, Universidade Federal do Rio de Janeiro, 2004), 71.

16 De acordo com Evaldo Cabral de Mello, "a Restauração portuguesa fora um golpe de Estado levado a cabo por estratos médios da nobreza que ao contrário da alta aristocracia, não havia se beneficiado dos favores da Coroa Castelhana na conjuntura da pressão fiscal decorrentes das reformas do Conde duque de olivares, e que preferiram lidar com um rei fraco, seu conterrâneo, do que o monarca espanhol. Evaldo Cabral de Mello. O negócio do Brasil: Portugal, os Países Baixos e o Nordeste (1641-1669). (São Paulo: Companhia das Letras, 2011).

17 Gama, "O Conselho", 79.

18 Marcello José Gomes Loureiro. "Iustitiam Dare: a gestão da Monarquia pluricontinental. Conselhos 
que demandavam maior urgência, como o financeiro, o de defesa do próprio reino e o das relações com os demais reinos vizinhos ${ }^{19}$.

\section{A mui leal e heroica ${ }^{20}$}

Na América, o Vice-rei Marques de Montalvão logo aceitou D. João IV como legítimo rei, seguido pelo governador do Rio de Janeiro, Salvador Correa de Sá e Benevides. Esta aceitação imediata acredita-se que tenha ocorrido pela possibilidade da nova administração apreciar os interesses locais ${ }^{21}$. Contudo, a notícia sobre o novo rei de Portugal chegou em um momento muito complicado nas Capitanias do Sul.

No Rio de Janeiro, por exemplo, duas facções disputavam o poder local: a do próprio Salvador e a dos descendentes da Família Mariz ${ }^{22}$. Além disso, havia uma forte disputa entre os jesuítas e os predadores de índios, os quais desejavam a expulsão daqueles do território da capitania, tal qual ocorrera em São Paulo.

Vale lembrar o prestígio que os jesuítas gozavam na capitania, e que eram apoiados e respaldados "junto aos governadores, sobretudo pela poderosa família Sá"23. A situação conflituosa piorou quando D. Filipe IV, em 1640, decretou a proibição da escravização dos índios e exigiu a liberdade dos cativos. O decreto real provocou a insurgência dos moradores e do Senado da Câmara contra os inacianos, mentores do ci-

superiores, pactos, articulações e o governo da monarquia pluricontinental portuguesa (1640-1668)". Tese de Doutorado, Universidade Federal do Rio de Janeiro; Ecole des Hautes Etudes em Sciences Sociales, 2014).

19 Segundo D. Francisco Manuel de Melo, D. João IV teria sido aconselhado pelo Secretário Francisco Lucena a não alterar demasiada a estrutura governativa, o que implicava não conceder demasiadas mercês aos aclamadores nem retirar escandalosamente ofícios a oficiais da coroa. Assim, não gerava a revolta de possíveis oficiais destituídos, podendo manter-se alguns dos aclamadores na expectativa de recompensas. O discurso político procurou enfatizar a ideia de que o novo rei deveria ouvir os Conselhos, os Tribunais, as Cortes. Foi precisamente essa uma das principais tarefas que D. João IV teve pela frente nos primeiros anos da Monarquia Restaurada. Gama, "O Conselho", 79.

20 Em 1642 a cidade do Rio de Janeiro recebeu o título de Mui leal e heroica. Em virtude disso, os cidadãos fluminenses receberam "os mesmos privilégios, honras e liberdades conferidos por carta régia de $1^{\circ}$ de junho de 1490 aos cidadãos do Porto [...]. Esses privilégios atribuíam-lhes certas prerrogativas de fidalguia, e à cidade, o título de "Leal". Uma primeira observação a se fazer acerca desses privilégios é o fato de serem concedidos aos cidadãos e não a todos os habitantes das cidades contempladas. Por cidadãos entendiam-se aqueles que por eleição desempenhavam ou tinham desempenhado cargos administrativos nas câmaras municipais - vereadores, procuradores, juízes locais, almotacés, etc. - bem como seus descendentes. Entre as prerrogativas a que tinham direito estavam as distinções de não serem metidos a tormentos por quaisquer malefícios que tivessem cometido, salvo não poderem ser presos por nenhum crime, somente como eram e deveriam ser os mesmos fidalgos, e de lhes ser permitido portar quaisquer tipos de votos. Maria Fernanda Bicalho. A cidade e o império: o Rio de Janeiro no século XVIII. (Rio de Janeiro: Civilização Brasileira, 2003), 322-323.

21 Barros, "Negócios...”, 87.

22 Durante o seu governo, Salvador Benevides sofreu oposição dos colonos que rivalizavam com a oligarquia dos Sá e desafiavam o seu poder, a fim de conquistarem para si cargos importantes, mercês e prestígio local, na tentativa de garantir dessa forma, a expansão de seus patrimônios.

23 Maria Regina Celestino Almeida. "Escravidão indígena e trabalho compulsório no Rio de Janeiro colonial" Revista Mundos do Trabalho 6.12 (2014): 12. 
tado decreto ${ }^{24}$. Como justificativa para revolta, deve-se destacar que a nova legislação acarretaria prejuízos aos referidos moradores, uma vez que a mão de obra autóctone em meados do século XVII era amplamente empregada, sendo ainda essencial como força de trabalho na capitania fluminense ${ }^{25}$.

Diante desse cenário, a chegada de um monarca diferente poderia traçar outras perspectivas já que um novo governo, dependente do apoio local, poderia abrir novas possibilidades e oferecer garantias na defesa dos interesses de determinados grupos. Para os colonos envolvidos com o comércio triangular Rio-Buenos Aires-Angola e com o contrabando, a situação poderia permanecer inalterada caso pudessem contar com a conivência de autoridades espanholas.

O Rio de Janeiro teria pouco a perder ao se posicionar ao lado da Casa de Bragança, e Salvador Correa de Sá e Benevides muito se beneficiaria pelo fato dos jesuítas, um importante grupo de pressão que o apoiava ${ }^{26}$, terem boas relações com D. João IV, o que poderia lhe conferir facilidades em obter favores do novo rei $^{27}$. Vale lembrar, que a aceitação da Restauração pelas autoridades fluminenses era de grande importância para a Coroa portuguesa, dada a posição estratégica da região para o comércio com o Rio da Prata e a prata oriunda dessa mercancia ${ }^{28}$.

No campo institucional a nova dinastia procedeu "uma reforma com a criação de novos órgãos centrais, que tinham por objetivo fortalecer o sistema polissinodal"29. Foi criado o Conselho de Guerra e o Conselho Ultramarino (1642) ${ }^{30}$, este último um órgão responsável por superintender toda a atividade colonial e atender a grande parte das matérias do ultramar ${ }^{31}$. O novo órgão colegiado, segundo Marcos Sanches, permi-

24 Almeida, "Escravidão...", 16.

25 Almeida, "Escravidão...", 11.

26 Salvador Correa de Sá e Benevides contou com o apoio dos jesuítas, ordem pela qual possuía grande apreço. Conhecedor da força e poder dos inacianos soube utiliza-los a seu favor, numa troca de apoio recíproco. Vivaldo Coaracy. O Rio de Janeiro no século dezessete. (Rio de Janeiro: José Olympio, 1965), 89.

27 Barros, "Negócios...", 97.

28 Em 1641, D. João IV concede a mercê de governador e capitão-mor do Rio de Janeiro a Salvador Correa de Sá e Benevides, em reconhecimento a serviços prestados a Coroa. Nesta mercê é elencado não só os referidos serviços prestados por Benevides ao longo de sua trajetória nos trópicos, mas também os de seus ascendentes, no que dizia respeito aos feitos e uso de recursos próprios para a manutenção e defesa da capitania. Como podemos inferir, a preservação de Salvador Benevides no cargo atendia não só a estratégia da Coroa para conquistar o apoio oriundo dos grupos locais na legitimação do novo monarca, como também a manutenção do status quo, já que este era membro de uma família que há muito governava o Rio, sendo um bom conhecedor da realidade da capitania e da própria colônia. (Cf. ANTT- Registro geral de Mercês, Mercê da Torre do Tombo, livro 8, fl. 148-149. PT/TT/RGM/Q/0008/49063. Mercê concedida a Salvador Correa de Sá e Benevides para desempenhar a função de governador e capitão-mor da Capitania do Rio de Janeiro em 1641).

29 Gama, "O Consehlo...", 80.

30 De acordo com Marcello Loureiro "os conselhos régios eram considerados tradicional e comumente espaços onde o rei poderia exercitar e preparar certas virtudes, como a prudência e a sabedoria. Em alguma medida, conselheiros assessoravam, mas também limitavam a ação régia, porque condicionavam suas decisões, embora essas não estivessem necessariamente sujeitas aos Conselhos." Loureiro, "Justitiam...", 182.

31 Regimento do Conselho Ultramarino. Cit. em Marcos Carneiro Mendoça. Raízes da formação 
tiu o esvaziamento "da atuação do Conselho da Fazenda sobre as áreas coloniais"32. Muitas das atribuições dessa instituição passaram para o novo tribunal, como, por exemplo, as questões aduaneiras. A falta de uma rígida hierarquia jurisdicional, assim como a inexistência de uma repartição de competência bem definida entre os conselhos, era um dos motivos das divergências entre esses órgãos. Em contrapartida, as suas decisões, por intermédio de consultas e pareceres, reafirmavam o caráter corporativo do governo, atualizando a imagem do rei como árbitro e mantenedor da harmonia entre as diferentes instituições ${ }^{33}$.

Inspirado no antigo Conselho da Índia do período filipino, o Conselho Ultramarino incorporou grande parte do regimento de $1604^{34}$. Sua criação teve como justificativa a não existência no Reino de Portugal de um órgão que tratasse exclusivamente dos assuntos ultramarinos ${ }^{35}$. Pelo referido conselho passaram várias questões importantes sobre a administração ultramarina. Visava ainda "estreitar a comunicação política com os distantes vassalos" ${ }^{\prime 36}$. Cabia aos seus integrantes assistir o rei, preparar e analisar a resolução de negócios para que o soberano pudesse decidir. As questões mais relevantes eram submetidas ao monarca, porém as de rotina podiam ser tratadas diretamente pelos oficiais encarregados dos assuntos em pauta ${ }^{37}$. A ocupação de um cargo nesse Conselho era objeto de grande prestígio na sociedade lusitana e pelos seus quadros passaram nomes que se destacaram na administração colonial, como o do ex-governador e capitão-mor da Capitania do Rio de Janeiro Salvador Correa de Sá e Benevides e o de Jorge Mascarenhas, o marques de Montalvão, Vice-rei do Brasil, entre outros.

\section{Fiscalidade e Alfândega}

Coube a D. João III instituir a Provedoria na colônia, juntamente com o Governo-geral em 1548. Entretanto, o papel adotado pelos provedores na colônia em muito se diferenciava da sua atividade no Reino, onde se ocupavam, sobretudo, das "fazendas

administrativa do Brasil. (Rio de Janeiro, IHGB, 1972), 589-601.

32 Sanches, "Fiscalidade...", 2.

33 Maria Fernanda Bicalho. "Entre a teoria e a prática: dinâmicas políticos e administrativas em Portugal e na América portuguesa. (séculos XVII e XVIII)”. Revista de História 167 (2012): 80.

34 Marcelo Caetano. Do Conselho Ultramarino ao Conselho do Império. (Lisboa: Agência Geral das Colônias/Editorial Ática, 1943), 25.

35 De acordo com Edval Barros "o Conselho Ultramarino foi apenas um dos polos de deliberação quanto à política a ser adotada para as conquistas no período de guerra. Interesses particulares, como os de Salvador Correa de Sá [e Benevides], ou fortes grupos de pressão, como os negociantes ligados à Companhia Geral de Comércio, continuamente ameaçavam as prioridades estabelecidas pelos conselheiros e solaparam sua autoridade e legitimidade." Barros, "Negócios...", 33.

36 Loureiro, "Justitiam...", 184.

37 Charles Boxer. Salvador de Sá e a luta pelo Brasil e Angola. São Paulo: Companhia Editora Nacional, 1973), 173. 
dos ausentes" $" 38$.

Em terras americanas, o Regimento de Antônio Cardoso de Barros inovou ao criar "um sistema centralizado e articulado de controle dos direitos reais e da economia do espaço colonial" "39. Barros, como titular do cargo de Provedor-mor, tinha a missão de colocar em ordem a mui desordenada administração da Fazenda. Esse regulamento tinha por objetivo, entre outros, o de prover as capitanias com Alfândegas. Com amplo leque de determinações voltadas para a implantação dos mecanismos de arrecadação e fiscalização, o regimento visava promover a aquisição de receitas e o controle de despesas. Foram anexadas ao instrumento normativo as disposições legais destinadas aos provedores das capitanias. Com 53 artigos, essas normas se ocupavam da montagem do aparato fiscal em nível local.

Por meio dessas normas, instituiu-se o regime fiscal fazendário, o ano fiscal e era evidente a preocupação de se evitar a evasão de impostos, o que demonstrava o reconhecimento pela Coroa do valor de suas possessões no ultramar e o descuido como era tratada até então a arrecadação fiscal na colônia.

A Restauração manteve em linhas gerais essa mesma estrutura organizacional e administrativa, procurando adaptar tal estrutura às necessidades e aos interesses da nova conjuntura ${ }^{40}$.

Do ponto de vista econômico, o período da Restauração se destacou pela mudança do eixo comercial do Oriente para a América, já que a perda da hegemonia marítima e da partilha das rotas de comércio daquela região possibilitou maior interesse pela exploração da colônia americana lusa.

Nesse contexto, o Brasil desempenhou um papel marcante no Império português devido aos recursos provenientes da exploração colonial e chegou a ser considerado a "vaca leiteira da Coroa"41. Vale lembrar que a moeda que sustentava a guerra da Restauração era proveniente, dentre outras mercadorias, do açúcar e de outros produtos coloniais brasileiros como o tabaco e pau-brasil ${ }^{42}$. Assim, era da sua colônia americana que o rei D. João IV retirava os cabedais para fazer frente às suas despesas na Europa ${ }^{43}$.

No século XVII, Portugal participou profundamente do conjunto econômico atlântico ${ }^{44}$, sendo o comércio do Brasil o que sustentava as suas Alfândegas ${ }^{45}$. A mesma

38 Pedro Puntoni. "A Provedoria-mor: fiscalidade e poder no Brasil colonial". O Brasil na monarquia Ibérica. Ana Paula Meniage et al. (São Paulo: Alameda, 2014), 64.

39 Puntoni, "A Provedoria-mor...”, 65-66.

40 Sanches, "Fiscalidade...", 1.

41 Jorge Caldeita. A nação mercantilista: ensaio sobre o Brasil. (São Paulo: Editora 34, 1997), 165.

42 Vitorino Magalhães Godinho. "Portugal, as frotas do açúcar e as frotas do ouro". Revista Vértice 92,93,94. (1951): 73.

43 França, "Portugal...", 400.

44 Godinho, "Portugal...", 72.

45 França, "Portugal...,", 398. 
opinião era compartilhada pelo conde camareiro de D. João IV, que alegava que "sem o Brasil não rendiam as Alfândegas"46.

Com a interrupção do intercâmbio de Angola, Brasil e Buenos Aires ${ }^{47}$, a situação fiscal fluminense foi severamente agravada. E com a queda da movimentação portuária supomos que tenha ocorrido a retração de recolhimentos de impostos na Alfândega do Rio, já que a diminuição de mercadorias em circulação no porto provocava decréscimo na arrecadação. Evidência disso é que a mando do governador Salvador Correia de Sá e Benevides, em 1642, o provedor da Fazenda Real, Pedro de Souza Pereira, esteve com os oficiais da Câmara para solicitar a continuação dos subsídios dos vinhos, como no tempo do rei Filipe, para atenuar a falta que faziam os rendimentos dos "direitos dos escravos de Angola e de Buenos Aires e Canárias que importavam nesta cidade". 48

Por isso foi grande a preocupação do rei D. João IV de restaurar o comércio com Buenos Aires. Em fevereiro de 1641, o monarca autorizou que seus vassalos, tanto do Reino quanto do Estado do Brasil, negociassem com os súditos da Coroa de Castela das Índias Ocidentais. Planejava assim aumentar o recolhimento dos direitos pagos nas alfândegas. ${ }^{49}$

Eu El Rei faço saber aos que este meu alvará virem, tendo consideração ao bem que desejo fazer a meus vassalos, assim deste Reino como do Estado do Brasil, Guiné e mais conquistas dele, e folgar que o comércio delas se aumente em utilidade sua: Hei por bem de lhes permitir que possam tratar e comerciar com os vassalos da Coroa de Castela nas Índias Ocidentais levando a elas negros de Cabo Verde e Guiné, para que com isto recebam as utilidades que se espera deste comercio e cresça em rendimento de minhas alfândegas, evitando juntamente com esta permissão os interesses que os estrangeiros tem com os negros que levam das ditas partes às Índias de Castela, e não lograrem os frutos que produzem as Conquistas deste Reino com declaração que as pessoas que houverem de navegar para as ditas partes hão de se aprovar meu Conselho Ultramarino, e serão obrigadas a meter nos Estados do Brasil e Maranhão a terça parte dos negros que levarem às Índias. ${ }^{50}$

O rei insistia para que se recorresse a todos os meios possíveis para esse fim, uma vez que o comércio com essa região era fundamental para manutenção da Coroa.

$46 \quad$ Alfredo Sousa Botelho. Subsídios para a história das guerras de Restauração no mar e além-mar. (Lisboa: Agência geral das colônias, 1940), 31.

47 José Gonçalves Salvador. Os cristãos-novos e o comércio no Atlântico meridional. (São Paulo: Pioneira/MEC, 1978), 374.

48 AHU, ACL, Rio de Janeiro, Caixa 2, Doc. 218. Solicitação do Provedor da fazenda Real do Rio de Janeiro Pedro de Souza Pereira a câmara da Cidade para que seja prorrogada a cobrança dos subsídios em razão da falta que fazia os rendimentos dos direitos dos escravos vindos de Angola. (1642)

49 Alvará de 2 de fevereiro de 1641. Cit em. Mendoça. Raizes..., 89.

50 .Alvará de 2 de fevereiro d e1641. Cit em. Mendoça. Raízes..., 89. 
O governador-geral Antônio Teles de Almeida tentou restabelecer o comércio com o Rio da Prata, mas não obteve sucesso na empreitada.

A essa altura havia outro problema: a ocupação de Angola pelos holandeses, que fez cessar a oferta de negros para as conquistas portuguesas. E como era de se esperar, sem negros a situação poderia a ficar complicada, já que estes além de mão de obra para o trabalho nos engenhos serviam como mercadoria que os castelhanos vinham buscar no Rio de Janeiro e que era contrabandeada no sul do Brasil. "Sem Angola ficava difícil relançar a carreira com Buenos Aires" ${ }^{51}$. Em carta ao Conselho Ultramarino, o monarca ressaltava: "Dizem mais que com toda a brevidade se deve acudir a Angola sem a qual praça não se pode sustentar o Brasil, nem este reino sem aquele Estado" 52 . Como se pode observar, a reconquista angolana era de muita importância para a consolidação da Casa de Bragança sobre a colônia, em especial na parte do nordeste ocupada pelos holandeses ${ }^{53}$.

Portugal, como se vê, encontrava-se em difícil posição, pois estava envolvido em uma guerra declarada com a Espanha e num embate com a Holanda, que já dominava Angola e parte do Brasil e ainda ameaçava as possessões na Ásia ${ }^{54}$.

Foi então que o rei aproveitou a presença de Salvador Correia de Sá e Benevides em Portugal e mandou consultá-lo sobre a melhor maneira de se resolverem os seguintes imbróglios: a reabertura do tráfico com Buenos Aires, a fim de restabelecer o fluxo de prata, e a retirada dos holandeses de Angola e Pernambuco ${ }^{55}$. A resposta dada por Benevides foi que não havia esperança de se "restabelecer em bases vantajosas o tráfico com Buenos Aires, uma vez que os portugueses não podiam continuar a fornecer negros escravos de Angola". ${ }^{56}$ Sugeriu então a conquista de Buenos Aires e a construção de uma fortaleza naquela província. Dizia ainda ser possível tirar muito proveito dessa conquista em carnes e couros para o Brasil. ${ }^{57} \mathrm{Em}$ relação à situação com Angola, Benevides considerava ser a mais importante de se estabelecer uma solução, já que aquela praça era essencial para o Brasil. Os portugueses dispunham não só da amizade com os "negros de lá" como mantinham três fortificações, ainda que

51 Almeida, "Escravidão...", 17.

52 AHU, ACL, Rio de Janeiro, Cx. 2, Doc. 305.

53 Antônio Carlos Jucá de Sampaio. Na encruzilhada do Império: hierarquias sociais e conjunturas econômicas no Rio de Janeiro (c.1650-c.1750). (Rio de Janeiro: Arquivo Nacional, 2003 ), 67.

$54 \quad$ Boxer, Charles. Salvador, 183.

55 AHU, ACL, Rio de Janeiro, Cx. 2, Doc. 305. Consulta ao Conselho Ultramarino sobre os alvitres apresentados por Salvador Correa de Sá para remediar os prejuízos causados pelos holandeses no Brasil e para introduzir o comércio com Buenos Aires (1644)

56 AHU, ACL, Rio de Janeiro, Cx. 2, Doc. 305. Consulta ao Conselho Ultramarino sobre os alvitres apresentados por Salvador Correa de Sá para remediar os prejuízos causados pelos holandeses no Brasil e para introduzir o comércio com Buenos Aires. (1644)

57 AHU, ACL, Rio de Janeiro, Cx. 2, Doc. 305. Consulta ao Conselho Ultramarino sobre os alvitres apresentados por Salvador Correa de Sá para remediar os prejuízos causados pelos holandeses no Brasil e para introduzir o comércio com Buenos Aires. (1644) 
precariamente ${ }^{58}$. A sugestão para a retirada dos holandeses no Brasil, segundo Benevides, deveria partir do governador-geral, que instigaria secretamente nos colonos a prática de incêndios nos canaviais pernambucanos e outros atos de sabotagem contra os invasores, até que o território se tornasse um fardo e esses se inclinassem a ouvir a proposta de compra da região e de Angola, mediante uma vultosa indenização. ${ }^{59}$

As propostas de invasão de Buenos Aires e sabotagem em Pernambuco foram rechaçadas. A primeira porque em tempos de tantos apertos não convinha à Coroa lançar mãos de novas conquistas e a segunda porque seria melhor optar pela via diplomática. Já em relação à reconquista de Angola, o conselho de Benevides foi acatado. ${ }^{60}$

Além dos problemas citados acima, outro era bastante prejudicial ao comércio: a pirataria.$^{61}$ Essa, que já era praticada nos mares da América lusa, desenvolveu-se consideravelmente, segundo Felisbello Freire, com a invasão holandesa nas capitanias do Norte, com a apreensão de navios que seguiam para o reino e suas respectivas $\operatorname{cargas}^{62}$.

Para se ter ideia da fragilidade das embarcações usadas no tráfico com o Brasil, basta verificar que eram compostas basicamente de caravelas e outros navios de pequeno porte construídos em Portugal ou fretados de outros reinos "amigos" europeus. De acordo com Boxer: "Essa drenagem, pesada e incessante, de que a navegação portuguesa era vítima, devia fatalmente causar grandes prejuízos a Lisboa, motivo pelo qual o uso de comboios era assunto de discussão entre os conselheiros do rei" ${ }^{63}$.

A sugestão para que os navios que entrassem ou saíssem do Brasil viajassem em comboios havia sido oferecida desde o período da União Ibérica. D. Filipe IV já dera ordem para que o assunto fosse discutido no Conselho de Portugal, mas nada de concreto foi estabelecido e nem mesmo as sugestões para se munirem de forma mais eficiente as embarcações foram aceitas ${ }^{64}$. Os simpatizantes da ideia do sistema de comboios afirmavam que os navios desarmados não ofereciam qualquer segurança

58 AHU, ACL, Rio de Janeiro, Cx. 2, Doc. 305. Consulta ao Conselho Ultramarino sobre os alvitres apresentados por Salvador Correa de Sá para remediar os prejuízos causados pelos holandeses no Brasil e para introduzir o comércio com Buenos Aires. (1644)

59 AHU, ACL, Rio de Janeiro, Cx. 2, Doc. 305. Consulta ao Conselho Ultramarino sobre os alvitres apresentados por Salvador Correa de Sá para remediar os prejuízos causados pelos holandeses no Brasil e para introduzir o comércio com Buenos Aires. (1644)

60 . AHU, ACL, Rio de Janeiro, Cx. 2, Doc. 305. Consulta ao Conselho Ultramarino sobre os alvitres apresentados por Salvador Correa de Sá para remediar os prejuízos causados pelos holandeses no Brasil e para introduzir o comércio com Buenos Aires. (1644)

61 Luiz Filipe de Alencastro também atribui às guerras "intermetropolitanas da segunda metade do século XVII" os motivos que levaram Portugal a armar as frotas do comércio para o transporte do açúcar em segurança até a metrópole. Luiz Felipe Alencastro. O trato dos viventes: formação do Brasil no Atlântico Sul. (São Paulo: Companhia das Letras, 2000) 28.

62 Felisbello Freire. História da Cidade do Rio de Janeiro (1564-1808) (Rio de Janeiro: Revista dos Tribunais, 1912), 148.

63 Boxer, Salvador..., 194.

64 Boxer, Salvador..., 194. 
e que desse fato se aproveitavam os corsários holandeses e demais inimigos. Uma carta do governador-geral D. Luís de Sousa ao rei relata a quantidade de açúcar que era perdida no trajeto do Brasil para a Europa devido à ação de corsários no Atlântico. D. Luís afirma que pelos registros dos livros de despachos das alfândegas na colônia seria possível verificar o dano notável à Fazenda Real, já que as mercadorias que chegavam ao seu destino eram em número menor do que o apontado nos referidos livros de saída. Alegava ainda que a perda não era proveniente de problemas no mar, pois os navegantes já estavam muito práticos nessa rota, mas sim dos roubos dos inimigos da Coroa, como os holandeses, ingleses, mouriscos e turcos.

[...] porque a quantidade de açúcar e mais drogas nomeadas se fazem no dito estado, nele se não gastam, para este reino se carregam os direitos que se pagam, coisa sabida pelos livros das alfândegas se verão, só haverá quem me diga que não chegam a este reino a quantidade de drogas que aqui aponto, assim o confesso, e para ver se com mostrar a Vossa Majestade esta clareza se pode remediar dano tão notável assim a sua real fazenda como ao bem comum de seus vassalos faço estes apontamentos. Primeiramente a experiência tem mostrado que de muitos anos a esta parte não se tem perdido no mar navio que vinha daquele estado, porque é uma viagem muito sabida em que os mareantes andam muito práticos, todos os que faltam roubam os inimigos desta Coroa, holandeses, ingleses, mouriscos e turcos. ${ }^{65}$

De acordo com o governador-geral, os corsários tomavam mais de 35 navios por ano, que levavam não só açúcar, mas também tabaco, pau-brasil, couro e conservas.

As objeções ao sistema das frotas vinham dos lavradores de cana, dos donos de navios e de seus comandantes e dos negociantes. As refutações diziam respeito a esse tipo de sistema necessitar navios maiores e providos de canhões, o que só poderia ser oferecido por indivíduos ricos ou pela Coroa. Além disso, os riscos de deterioração das mercadorias eram grandes, visto que os navios só poderiam zarpar depois que todas as embarcações do comboio estivessem reunidas no porto da Bahia. A baixa de preços que era provocada pelo excesso de oferta nos portos portugueses ${ }^{66} \mathrm{com}$ a chegada dos navios do comboio era outro problema que desestimulava a adoção desse tipo de navegação com proteção. ${ }^{67}$

Após muita discussão, chegou-se à conclusão de que seria melhor os navios terem a liberdade de partir de Portugal independentemente, sem os galeões de escol-

$65 \quad 1^{\circ}$ Livro do Governo do Brasil, CNCDP, 2001, p. 50.

66 Boxer, Salvador..., 197.

67 Tanto a quantidade como os preços dos produtos disponíveis variavam drasticamente, a depender da data de chegada ao porto das frotas de Lisboa, do Porto e das ilhas vinicultoras do Atlântico. Se esses atrasavam, os preços podiam disparar de $50 \%$ a $100 \%$ acima dos valores habituais, para logo depois despencar assim que os navios reapareciam. Dauril Alden. "Vicissitudes of trade in the Portuguese Atlantic Empire during the first half of the eighteenth century: a review article" The Americas 32.2 (1975): 287. 
ta, e no retorno viajarem em comboios, com ponto de encontro na Bahia. Em 1644 o rei impôs o regimento que deveria ser usado nas viagens das frotas no Brasil, para corrigir a falta de segurança da navegação. Ao viajar juntos os navios garantiriam a proteção das mercadorias. O citado regimento dispunha a respeito da guarnição, dos seus deveres, fixava a tonelada de cada navio, sua carga, o valor do frete e das avarias e a data da viagem, entre outras determinações ${ }^{68}$. Salvador Correia de Sá e Benevides foi escolhido para ser o comandante da frota, após este ter se candidatado a fornecer, "por assento, os dois galeões de escolta, de sua propriedade com 400 toneladas e 24 peças de artilharia na condição de ser provido em general da frota" ${ }^{\prime \prime}$.

O período também foi marcado pelo empreendimento de esforços para o "fortalecimento e a reorganização da exploração econômica no ultramar" ${ }^{70}$. Assegurar a manutenção da reserva de mercado da colônia para a metrópole ${ }^{71}$, ou seja, o exclusivo comercial, que vinha se impondo gradativamente desde os alvarás de 1591 e $1605^{72}$, era fundamental para o sistema colonial que estava se constituindo.

Para o sustento da Guerra da Restauração era necessário haver dinheiro e o meio mais efetivo de conquistá-lo seria com comércio. Esse, por sua vez, para se preservar e desenvolver precisava de segurança e liberdade para os mercadores. $\mathrm{O}$ volume de negócios e o lucro mais elevado eram dados pelo comércio colonial, que era também o que exigia maior investimento de capitais, pois envolvia transações a crédito, despesas com transporte e dispêndio de tempo com as viagens.

Os Estados, assoberbados de despesas com a própria administração e com uma fiscalidade que não conseguia suprir todas as suas necessidades financeiras, tinham dificuldade de dispor de recursos para manter por conta própria o comércio colonial.

68 Freire, História..., 149.

69 Leonor Freire Costa et. Al. "A Circulação do Ouro do Brasil: 0 Direito DO 1o/o" Working Papers GHES - Office of Economic and Social History (2002): 500-501.

70 Mont Serrat, Pablo Oller. "O império português no Atlântico: poderio, ajuste e exploração (16401802)". Tese (Doutorado em História). (São Paulo: Universidade de São Paulo, 2013), 13.

71 Podemos verificar a preocupação com o exclusivo comercial no documento em que Mateus de La Haia Leão, comerciante francês solicita permissão para ir ao Rio de Janeiro com navios cheios de fazendas para buscar sua mulher. A resposta da autoridade lusa demonstra a preocupação de se manter a reserva de mercado para os portugueses. Segundo o manuscrito, tanto o povo quanto os homens de negócio eram contrários a petição do francês, por acharem que o comércio de estrangeiros acarretaria em danos a Fazenda Real e ainda prejuízos ao povo e a mercancia de Portugal. .Lembrava ainda que "os três reis deste reino foram sempre tão ciosos de irem estrangeiros ao Brasil (ainda que fossem amigos e confederados) que foram estabelecendo rigor das leis e tão apressadas execuções delas contra os estrangeiros que fossem à aquelas partes, em tanto que deram alçada aos capitães das capitanias do Estado do Brasil, que cada um em sua capitania com o ouvidor dela condenasse a morte natural todos os estrangeiros que aportassem nas ditas capitanias e lhe confiscassem seus bens e dessem suas sentenças a execução sem apelo nem agravo”. (AHU, ACL, CU, 017, Cx.2, Doc. 98, Avulsos- Requerimento do capitão francês Matheus de La Haia Leão ao rei D. João IV solicitando licença para ir para o Rio de Janeiro com três navios carregados de mercadorias para buscar sua mulher e filhos).

72 Estes alvarás restringiam o comércio com estrangeiros na colônia. Entretanto, este comércio nunca foi totalmente extinto, fosse ele legal ou mesmo ilegal. Rodrigo Ricupero. "O exclusivo metropolitano no Brasil e os tratados diplomáticos de Portugal com a Inglaterra (1642-1661)”. Revista História 176 (2017). 
Os fatores naturais, associados à precariedade de meios técnicos, à rivalidade e à concorrência entre as nações, além da profusão do corso e pirataria, traziam grande perigo à navegação. Foi da combinação desses elementos que surgiu a conveniência de se criar uma companhia particular para a exploração do comércio colonial. Só ela poderia permitir "ajuntar os capitais em excesso dos particulares, suprir a carência de poder monetário do Estado, realizar o negócio e obter grandes lucros" ${ }^{\text {"73. }}$.

Os recursos para a criação dessa Companhia foram oriundos dos homens de negócio, cristãos-novos ${ }^{74} \mathrm{e}$ também de "cristãos-velhos, alguns até familiares do Santo ofício ou seus parentes próximos"75, e demais vassalos, sem que houvesse gasto algum da Fazenda Real ${ }^{76}$. Essa Companhia deveria manter uma frota com 36 naus de guerra, que, divididas em duas esquadras com 18 embarcações, escoltariam os navios entre Portugal e o Brasil, dariam guarda às embarcações e fazendas que fossem ou voltassem dessas partes e as protegeriam dos inimigos, a fim de garantir o comércio entre as regiões e os direitos das alfândegas. Esse comboio era pago com os direitos ou as avarias da seguinte forma, de acordo com o Art. 23 do Estatuto da Companhia de Comércio do Brasil:

Seiscentos réis por caixa de açúcar ou tabaco, trezentos réis por barril, cem reis por rolo de tabaco fora das caixas, seiscentos réis por saca de algodão, vinte réis por cada couro, a título de segurança dos navios e fretes, e cento e quarenta réis, cento e vinte réis e cem réis por arroba de açúcar, respectivamente branco, mascavo ou de panela. ${ }^{77}$ Cento e cinquenta por arroba do tabaco, e oitenta réis por cada couro, a titulo de segurança das mercadorias transportadas; cobradas todas por feitores da Companhia nas Alfândegas do Reino como se fossem impostos aduaneiros. ${ }^{78}$

Nada era pago ao comboio pela viagem de ida da metrópole para a colônia. Todo o pagamento devido era feito a prazo e, além desse rendimento dos navios mercantes

73 Gustavo Freitas. “A Companhia Geral do Comércio do Brasil [1649-1720]: subsídios para a História Econômica de Portugal e Brasil” Revista de História (1951), 323.

74 De acordo com o alvará: "E entendendo que o principal meio, com que se poderia aumentar e conservar a dita Companhia, seria não ficarem sujeitas a sequestro, confiscação, e condenação, as fazendas, e bens dos ditos homens de negócio, e de gente de nação, acontecendo que sejam presos, ou condenados pelo Santo Ofício da Inquisição, pelos crimes de heresia, apostasia, ou judaísmo" (Alvará Real de 6 de fevereiro de 1649. Cit em. José Justino de Andrade Silva. Colleção Chronológica da Legislação Portuguesa. (Lisboa: Imprensa de J.J.A. Silva, 1854).

75 Costa et. Al. “A Circulação...”, 481.

76 Padre Antônio Vieira, cristãos-novos, alvará de isenção de confisco: três tópicos dedutivos encadeados nas tradicionais interpretações da gênese da Companhia [...]. Leonor Freire Costa afirma que estudos recentes vêm quebrando essa cadeia de argumentos ao desvincular o sangue cristão novo da referida Companhia. Costa et. Al. “A Circulação...”, 481.

77 Espécie de açúcar inferior que se fazia com o licor que saía da parte de baixo das formas. Rafael Bluteau. Vocabulário português \& latino. (Coimbra: Collegio das Artes da Companhia de Jesus, 1728), 212.

78 Art. XXIII do Estatuto da Companhia de Comércio do Brasil. Cit em. Silva. Colleção.... 
escoltados, a Companhia contava com os fretes de navios de escolta, que mesmo sendo navios de guerra carregavam mercadorias. Entretanto, para que pudessem entrar em combate sua carga não poderia ultrapassar um terço da capacidade total ${ }^{79}$. De acordo com o Art. 20 do regimento, não podiam sair do Reino para o Estado do Brasil nenhum navio, caravela ou barco que não fosse escoltado pela Companhia, salvo em caso de necessidade de socorro àquele Estado, mas somente com licença real ${ }^{80}$.

A Companhia de Comércio do Brasil recebia ainda privilégios de natureza econômica e também política. Do que diz respeito à natureza econômica, pode-se observar o estanco ou monopólio de quatro dos principais gêneros importados: vinho, farinha, azeite e bacalhau. Dessa forma, nenhuma pessoa poderia levar tais produtos ao Brasil e os referidos produtos eram vendidos por exclusividade a 40 mil réis cada pipa de vinho, 1.600 réis cada arroba de farinha, 16 mil réis cada barril de azeite de seis almudes (25 litros) e 1.600 réis cada arroba de bacalhau. Também lhe eram asseguradas outras vantagens, como cedência pela Coroa de seis navios de guerra (Art. 13 do regimento), que a Companhia pagaria a prazo; isenção de parte do imposto sobre $\mathrm{o}$ vinho para o gasto dos seus navios ${ }^{81}$ nas mesmas condições dos que se destinava às armadas reais; direito de guardar as presas que fizesse; proibição da navegação fora do comboio, sob a pena de perder a embarcação a favor dela, bem como a proibição de se fabricar cachaça no Brasil para se evitar a concorrência do vinho do qual fazia estanco $^{82}$.

Em relação aos privilégios políticos, a Companhia se destacava pela "absoluta independência" em relação aos tribunais maiores e menores, mantendo-se como uma espécie de Conselho ou Tribunal Régio, podendo fazer consultas diretamente ao rei do mesmo modo que os Conselhos do Estado, Fazenda e Ultramarino ${ }^{83}$. De acordo com Gustavo Freitas, esse caráter de órgão de Estado era reforçado por algumas prerrogativas

[...]como o direito de um juiz conservador privativo, de alojamentos no Brasil, de armazenamento nas suas casas como se armazéns da alfândega fossem, de compra de vinhos, azeites, trigos e carnes em qualquer parte do Reino que entendesse, de requisitar embarcações e madeiras e mobilizar artífices e trabalhadores. ${ }^{84}$

Cabia ao Estado recrutar gente para as suas forças militares, e o serviço prestado nas armadas da Companhia era equivalente ao prestado na marinha ou no exército do

$79 \quad$ Freitas, “A companhia....", 89.

80 Art. XX do Estatuto da Companhia de Comércio do Brasil. Cit em. Silva. Colleção....

81 De acordo com o Art. XXVIII: “[...] pagarão só os direitos de entrada e saída que costumam pagar a Fazenda de Vossa Majestade, dos que vem para o apresto de suas Armadas Reais, que serão quinhentas pipas somente" (Estatuto da Companhia de Comércio do Brasil. Cit em. Silva. Colleção.

$82 \quad$ Freitas, "A companhia...", 89.

83 Freitas, “A companhia...”, 89.

84 Freitas, “A companhia...”, 90. 
rei. O Art. 32 estabelecia que a ofensa que se fizesse a qualquer oficial da Companhia, de obra, palavra, sobre matéria do seu ofício, seria castigada pelo conservador, como se fosse feita aos oficiais reais. ${ }^{85}$

Várias queixas surgiram contra a Companhia logo após sua fundação. As objeções tinham a ver com o descumprimento do contrato, já que a referida Companhia, além de não juntar o número de naus de guerras estabelecido, ainda não abastecia, como o previsto, a colônia dos produtos dos quais tinha monopólio, fazendo com que houvesse carestia e desabastecimento na colônia.

A primeira frota da Companhia de Comércio saiu de Lisboa em novembro de 1649 para o Brasil sob o comando do conde de Castelo Melhor, que vinha designado para ser o governador-geral do Brasil. Estava assim instituído o monopólio dos transportes e, por conseguinte, a Companhia também podia exercer forte influência nos preços e no comércio, já que, ao ser a única a levar as mercadorias do Brasil para a Europa, podia impor seus preços, negar-lhes o embarque e coagir os comerciantes a aceitarem suas condições. "Era do comércio, praticado por essa forma, que os organizadores da empresa contavam conseguir lucros, e não da indústria de transportes" ${ }^{86}$.

A insuficiência de gêneros trazidos por essa frota causou o desabastecimento do Rio de Janeiro e um aumento de preços dos produtos, o que gerou grave prejuízo à economia $^{87}$. Tal situação pode ser evidenciada pela informação do capitão Francisco da Cruz, que havia estado naquela parte e descreveu a situação em que se encontravam os moradores não só pela falta das mercadorias, mas por problemas referentes à venda do açúcar, o que influía no pagamento da infantaria ${ }^{88}$.

Por haver neste Conselho noticia que o capitão Francisco da Cruz havia vindo da Capitania do Rio de Janeiro a esta fosse enviado pelo Governador e Câmara da mesma praça representar a V. Majestade as necessidades que nela padecia [...] Se condenou que dissesse e representasse o preço que então valia por venda geral ou particular o vinho, azeite, farinha e bacalhau, que são os da Companhia Geral de Comércio. E se deles havia a abundância necessária e eram de levar grandes e também se havia vendas por segundas mãos na mesma capitania e por que preços. ${ }^{89}$

Além disso, a venda de pouca quantidade de gêneros trouxe prejuízo não só aos

85 Estatuto da Companhia de Comércio do Brasil. Cit em. Silva. Colleção....

$86 \quad$ Coaracy, O Rio..., 137.

87 Coaracy, $O$ Rio..., 138.

88 AHU, ACL, CU, Rio de Janeiro, Cx.3, Doc. 207.Informação do capitão Francisco da Cruz sobre o estado em que deixou a praça do Rio de Janeiro, descrevendo a falta de sal, azeite, vinho e bacalhau, gêneros comercializados pela Companhia Geral do Comércio do Brasil (1651).

89 AHU, ACL, Rio de Janeiro, Cx.3, Doc. 207. Informação do capitão Francisco da Cruz sobre o estado em que deixou a praça do Rio de Janeiro, descrevendo a falta de sal, azeite, vinho e bacalhau, gêneros comercializados pela Companhia Geral do Comércio do Brasil (1651). 
negócios fluminenses, mas também acarretou redução das arrematações de contratos e subsídios aplicados naquela praça ${ }^{90}$. Em carta ao rei D. Afonso VI, o governador Tomé Correia de Alvarenga relata:

Esta praça está limitada pelo pouco comércio padecendo a falta de gêneros a que se obrigada a Companhia Geral do Comércio meter neste Brasil pelo não haverem feito neste comboio e nas mais em tão pouca quantidade que sempre se experimenta o mesmo efeito. E pelo estado do comercio e senão meterem os gêneros estão as rendas de V. Majestade e subsidio aplicado a elas não prometendo avanço pela muita perda que alcançam os contratadores das ditas rendas. ${ }^{91}$

Dessa forma, podemos observar que a diminuição da atividade comercial afetou não só o abastecimento da capitania, mas também influenciou na arrecadação das rendas da Coroa e da Câmara.

Em vista disso, as tendências do período demonstram que as novas necessidades e os novos interesses da Coroa justificavam a crescente preocupação com o comércio e a eficácia da arrecadação fiscal. No que dizia respeito aos procedimentos alfandegários não houve nenhuma alteração, devendo ser seguidos os procedimentos estabelecidos para todo o Reino em relação à entrada e saída de mercadorias ${ }^{92}$, qual seja, o que constava no Foral da Alfândega de Lisboa (1587). Este Foral e o Regimento dos Provedores concedido ao Provedor-mor, Antônio Cardoso de Barros (1548), que regulavam as aduanas na Colônia americana lusa, estabeleciam que todas as naus e navios provenientes do Reino e de fora dele deveriam se dirigir diretamente a alguma parte onde houvesse Alfândega, para ali serem vistos, descarregarem e pagarem, se fosse o caso, a dízima das mercadorias que estavam trazendo.

Em relação à cobrança da dízima ${ }^{93}$, uma minuta do Conselho da Fazenda de

90 AHU, ACL, Rio de Janeiro, CX.3, Doc. 313. Carta do governador do Rio de Janeiro, Tomé Correia de Alvarenga ao rei [D. Afonso VI] informando a situação causada pela Companhia de Comércio desta praça, ao comercializar poucos gêneros acarretando na redução de arrematações dos contratos e dos subsídios aplicados naquela praça (1657).

91 AHU, ACL, Rio de Janeiro, CX.3, Doc. 313. Carta do governador do Rio de Janeiro, Tomé Correia de Alvarenga ao rei [D. Afonso VI] informando a situação causada pela Companhia de Comércio desta praça, ao comercializar poucos gêneros acarretando na redução de arrematações dos contratos e dos subsídios aplicados naquela praça (1657).

92 "Foi Vossa Majestade servido mandar-me declarar no Regimento do Oficio do Provedor da Fazenda e Juiz da Alfândega que me fez mercê em propriedade desta capitania que em todos os navios neste porto vierem fazer guardas e os despacha-se vindo e voltando na forma como é estilo nos mais do Reino." (AHU, ACL, Rio de Janeiro, Cx. 2, Doc. 200. Carta do Provedor da Fazenda Real do Rio de Janeiro, Pedro de Souza Pereira, ao rei [D. João IV] sobre a duvida dos mestres de três navios que comboiaram a frota da Companhia Geral de Comércio do Brasil em se por guarda e despachar na Alfândega os açúcares e drogas transportadas, solicitando em como proceder com os navios da Companhia (1650).

93 Existem várias lacunas em relação à documentação aduaneira, que não nos permite quantificar as receitas obtidas pela Alfândega fluminense. Entretanto, embora não tenhamos dados numéricos ou quantitativos 
1616 determinava que todos os navios portugueses que tivessem efetuado o pagamento desse tributo nas Alfândegas da metrópole, mostrando as certidões comprobatórias estariam isentos do novo pagamento nas Alfândegas brasileiras. Entretanto, as mercadorias da terra que fossem para qualquer outro lugar fora do Reino deveriam pagar nas aduanas da colônia, a dízima de saída. Para os navios pertencentes a mercadores de outros reinos que ao Brasil trouxessem ou levassem mercadorias para seus locais de origem teriam que satisfazer o pagamento do referido tributo da dízima na entrada e na saída dos portos brasileiros ${ }^{94}$.

Na segunda metade do século XVII, as alfândegas, além de suas atribuições originárias ${ }^{95}$, passam a ficar encarregadas de recolher o donativo para o casamento de Catarina de Bragança e para a paz de Holanda ${ }^{96}$. O pagamento de mais esse tributo

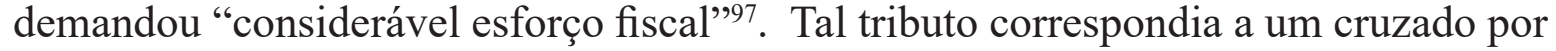
escravo que chegasse ao porto e $2 \%$ sobre todas as mercadorias que entrassem nas alfândegas, com exceção do azeite e dos vinhos ${ }^{98}$. Nesse sentido, a carta do abade frei Mauro de Assunção atribui ao pagamento desse donativo uma das causas da ruína do Rio de Janeiro, já que com mais esse tributo, que passou de voluntário para obrigatório, extrapolava-se a capacidade da população de contribuir para o fisco, dados os

para esse período, podemos inferir que a Alfândega, braço econômico e fiscal da administração, já tinha nesse momento uma atuação presente, fiscalizava e exercia controle sobre a movimentação comercial. A primeira justificativa que nos ocorre para tal ausência foi o incêndio ocorrido na Alfândega durante a invasão dos corsários franceses no século XVIII, que destruiu os seus armazéns a segunda é a perda para o tempo e a terceira o descaso das autoridades em fazer os registros da movimentação comercial nos livros contábeis. A leniência com que era tratada a arrecadação dos direitos régios era motivo de preocupação dos representantes do rei. A ausência dos oficiais da Coroa para a fiscalização já era sentida pelas autoridades que viviam nas capitanias, como comprova a carta do vice-rei Alberto de Áustria para o rei Filipe II de 1586: "Me pareceu que será serviço de vossa majestade mandar-lhe escrever que visite em pessoa todas as fortalezas daquele estado por haver muito tempo que não são visitadas e haver queixas dos ministros da justiça e fazenda que nela residem." (Carta do vice-rei Alberto de Áustria ao rei D. Filipe II. Archivo General de Siamancas, Secretaria Provinciales, Libro 1550, fl. 320).

94 AHU, Luísa da Fonseca, Bahia. Cx.1, D.51 - Minuta do Conselho da Fazenda acerca dos direitos dos navios que vão para Buenos Aires.

95 As Alfândegas eram as instituições encarregadas da aplicação de medidas de caráter econômico em ações que tinham por objetivo promover a regulação do mercado. Também respondiam pela supervisão das fronteiras marítimas, do controle de entrada e saída de navios, arrecadação de tributos incidentes sobre as mercadorias que circulavam pelos portos, e ainda garantidoras do exclusivo comercial, isto é, do monopólio imposto pela metrópole que proibia legalmente o comércio da colônia com os reinos estrangeiros, não só através de barcos ou de mercadores desses reinos, como através de barcos ou mercadores reinóis que partissem da colônia para outro local diferente de Portugal.

96 Letícia dos Santos Ferreira. "É pedido, não tributo: o Donativo para o casamento de Catarina de Bragança e a paz de Holanda. (Portugal e Brasil, c.1660-c.1725)" (Tese de Doutorado, Universidade Federal Fluminense, 2014), 109.

97 Puntoni, "A Provedoria-mor...", 4.

98 DHBN, v. 4, p. 99. Provisão que se enviou às capitanias deste Estado para se tirar o dote da Senhora Infanta e o que faltar para o ajustamento da paz (1662). 
problemas financeiros enfrentados pela capitania devido à Companhia de Comércio ${ }^{99}$. A crescente necessidade de recursos no decorrer do seiscentos para financiar as despesas militares da capitania fez com que por determinação real ${ }^{100}$ se transferisse para a Câmara Municipal os custos da defesa da cidade, permitindo que esta "administrasse sua própria fiscalidade para fins defensivos e os recursos financeiros dessa receita" 101.

Coube a este concelho administrar o "pagamento de impostos perenes e temporários lançados pela metrópole em ocasiões especiais, impor taxas ocasionais, arrendar contratos, arrecadar contribuições voluntárias, etc" ${ }^{102}$. Dessa forma, a Câmara assumiu a administração de imposições e subsídios tradicionalmente cobrados pela Fazenda Real ${ }^{103}$, tangendo aos oficiais camarários fluminenses a gestão do subsídio do vinho e da água ardente ${ }^{104}$. Tão logo esses produtos chegavam ao porto do Rio de Janeiro, um guarda era designado para entrar na embarcação a fim de manter vigia e impedir os descaminhos. Em seguida, o mestre do navio tinha por obrigação levar o livro do rol da carga até a Câmara e obedecendo a um rito, sob juramento, declarava o volume das mercadorias. A descarga era fiscalizada pelos edis e o dinheiro devido do imposto era pago diretamente a eles ${ }^{105}$, não passando dessa forma tais mercadorias pela alçada dos oficiais da Alfândega ${ }^{106}$.

99 AHU, ACL, Rio de Janeiro, Cx. 4, Doc. 373. Carta do procurador geral do Estado do Brasil José Moreira de Azevedo ao príncipe regente D. Pedro sobre uma carta do abade do Mosteiro de São Bento de Pernambuco, doutor frei Mauro de Assunção, em que informa as causas da ruína do comercio do Rio de Janeiro, indicando a forma como a influencia destes na escolha de pessoas para os cargos públicos, apontando as medidas que devem ser tomadas para ultrapassar a situação (1669).

100 " “...] O governador-geral Antônio Teles da Silva por ordem que diz trouxe de V. Majestade nos encarregou [Oficiais da Câmara] que com o dito governador Luiz Barbalho [Bezerra] procurássemos aceitasse este povo o subsídio dos vinhos[...] para que deste efeito se socorresse o presídio e fortificações da cidade pois da Fazenda Real não haviam rendimentos para isso e se bem que o grande aperto em que nos vemos e falta de dinheiro[...]" (AHU, ACL, CU, 017, Cx.2, D.113, Avulsos - Carta dos Oficiais da Câmara da cidade do Rio de Janeiro [ a respeito do] cumprimento da ordem régia para se por subsídio nos vinhos e vintena nos bens dos moradores a fim de socorrer a infantaria do Presídio do Rio de Janeiro, visto não ter a Fazenda Real rendimentos suficientes).

101 Figueiredo, Luciano Raposo de Almeida. "Equilibrio distante". Varia História 20.32 (2004): 144-175.

102 Maria Fernanda Bicalho. "As câmaras municipais no Império português: o exemplo do Rio de janeiro" Revista Brasileira de História 18.36 (1998): 251-580.

103 Miguel Dantas da Cruz. Um império de conflitos: o Conselho Ultramarino e a defesa do Brasil. (Lisboa: Imprensa de Ciências Sociais, 2015), 221.

104 Cruz, Um império..., 222.

105 Anais da Biblioteca Nacional, v. 46, 1924. p. 19. Inventário dos documentos relativos ao Brasil existentes no Arquivo da Marinha e Ultramar, organizado por Eduardo de Castro Almeida.

106 Tal informação pode ser comprovada pelo trecho seguinte: "E nova ordem de V. Majestade é para dar forma ao dito despacho me deu um explicável trabalho porque como das ditas fazendas se não costumava pagar direitos e por essa causa estava em estilo não virem muitas a Alfândega." (AHU- ACL- Rio de Janeiro- Cx. 12, Doc. 2394,2395. Rio de Janeiro, 19 de junho de 1700.Carta do Provedor da Alfândega acerca da cobrança da dízima de todos os gêneros entrados na Alfândega do Rio de janeiro, cujo os rendimentos os moradores desta cidade haviam oferecido para o custeio da infantaria com que de novo se aumentaram o efetivo da guarnição). 
Com o passar dos anos, o Rio de Janeiro passou a ganhar maior destaque no seio do Império português devido à descoberta de veios auríferos no centro sul da colônia, da fundação da Colônia de Sacramento e a colonização do sul. Em face da necessidade de maior proteção da cidade fez-se urgente o aumento da infantaria. Para isso seria necessário um incremento da arrecadação fiscal. O Conselho Ultramarino, que assumira responsabilidades militares com a Resolução de 1671, logo solicitou ao Governador Artur de Sá e Menezes que providenciasse meios suaves de se aumentar a arrecadação. Foi então que o referido governador se reuniu com a edilidade local, que ofereceu ao Rei (D. Pedro II) a dízima da Alfândega de todas as fazendas que entrassem de qualquer parte que fossem, e a efetivação dessa cobrança fez com que tal imposto aduaneiro se tornasse a maior arrecadação da capitania superando inclusive os dízimos, que sempre haviam liderado.

\section{Considerações finais}

A Restauração, embora tenha sido um momento de grande inflexão no campo político, não trouxe significativas mudanças no campo administrativo. A preocupação do novo rei em se distanciar das práticas desenvolvidas pelos reis anteriores, principalmente por D. Filipe IV e por seu valido, o Conde duque de Olivares, permitiu a revitalização das Cortes, dos Conselhos e dos Tribunais.

Para legitimar a nova dinastia, novos órgãos foram criados, dentre eles o Conselho Ultramarino, que tinha dentre suas atribuições se ocupar das matérias relacionadas com as partes ultramarinas. Em relação à fiscalidade, diante da falta de recursos para prover as necessidades da colônia, optou-se por transferir a administração de alguns tributos para as Câmaras.

No entanto, as Alfândegas continuaram sob a responsabilidade da Fazenda Real e desenvolveram um importante papel na medida em que eram as instituições responsáveis pela vigilância dos portos, pela cobrança de tributos e ainda pela manutenção do exclusivo comercial, este último, a peça chave do sistema colonial que foi se constituindo pouco a pouco ao longo do Seiscentos. No final desse século, a descoberta das minas de ouro na América Meridional provocou um incremento das atividades comerciais e o porto do Rio de Janeiro ganhou destaque, já que era por ali onde entravam e saíam as mercadorias que abasteciam as regiões mineradoras. Com isso, a aduana fluminense adquiriu um novo status, e a arrecadação do imposto da Dízima da Alfândega se sobrepôs inclusive ao dízimo, até então, o tributo mais rentável da capitania. 


\section{Referência Bibliográfica}

Aidar, Bruno. "Poder regional e fiscalidade na capitania de São Paulo, 1723-1808". Anais... XI Congresso Brasileiro de História Econômica. Vitória: ABPHE; UFES, 2015.

Alden, Dauril. "Vicissitudes of trade in the Portuguese Atlantic Empire during the first half of the eighteenth century: a review article" The Americas 32.2 (1975): 282-291.

Alencastro, Luiz Felipe. O trato dos viventes: formação do Brasil no Atlântico Sul. São Paulo: Companhia das Letras, 2000.

Almeida, Maria Regina Celestino. "Escravidão indígena e trabalho compulsório no Rio de Janeiro colonial" Revista Mundos do Trabalho 6.12 (2014): 11-25.

Araújo, Luiz Antônio Silva. "Contratos, comércio e fiscalidade na América portuguesa (1641-1730)" em Guerra e fiscalidade na Ibero-América colonial (séculos XVII-XIX). Coords. Ángelo Carrara et. Al. (Juiz De Fora: Ed UFJF, 2012).

Barros, Edval de Souza. "Negócios de tanta importância: o Conselho Ultramarino e a disputa pela condução da guerra no Atlântico e no Índico (1643-1661)". Tese de Doutorado, Universidade Federal do Rio de Janeiro, 2004.

Bicalho, Maria Fernanda. A cidade e o império: o Rio de Janeiro no século XVIII. Rio de Janeiro: Civilização Brasileira, 2003.

- "As tramas da política: política, conselhos, secretários e juntas na administração da monarquia portuguesa e seus domínios ultramarinos". Na trama das redes: política e negócios no império português, séculos XVI-XVIII. João Fragoso et. Al. Rio de Janeiro: Civilização Brasileira, 2010.

—_ "As câmaras municipais no Império português: o exemplo do Rio de janeiro". Revista Brasileira de História 18.36. (1998).

- "Entre a teoria e a prática: dinâmicas políticos e administrativas em Portugal e na América portuguesa. (séculos XVII e XVIII)". Revista de História 167 (2012): 75-98.

Bluteau, Rafael. Vocabulário português \& latino. Coimbra: Collegio das Artes da Companhia de Jesus, 1728. 
Botelho, Alfredo Sousa. Subsídios para a história das guerras de Restauração no mar e além-mar. Lisboa: Agência geral das colônias, 1940.

Boxer, Charles. Salvador de Sá e a luta pelo Brasil e Angola. São Paulo: Companhia Editora Nacional, 1973.

Caetano, Marcelo. Do Conselho Ultramarino ao Conselho do Império. Lisboa: Agência Geral das Colônias/Editorial Ática, 1943.

Caldeita, Jorge. A nação mercantilista: ensaio sobre o Brasil. São Paulo: Editora 34, 1997.

Carrara, Angelo Alves. Receitas e despesas da Real Fazenda no Brasil. Juiz de Fora: Editora UFRJ, 2009.

Coaracy, Vivaldo. O Rio de Janeiro no século dezessete Rio de Janeiro: José Olympio, 1965.

Costa, Leonor Freire, et. Al. "A Circulação do Ouro do Brasil: 0 Direito DO 1o/o" Working Papers GHES - Office of Economic and Social History (2002).

Cruz, Miguel Dantas da. Um império de conflitos: o Conselho Ultramarino e a defesa do Brasil. Lisboa: Imprensa de Ciências Sociais, 2015.

Escudero, José Antonio. El Rey: História de la monarquia v. 1. Barcelona: Planeta, 2008.

Ferreira, Letícia dos Santos. "É pedido, não tributo: o Donativo para o casamento de Catarina de Bragança e a paz de Holanda. (Portugal e Brasil, c.1660-c.1725)". Tese de Doutorado, Universidade Federal Fluminense, 2014.

Figueiredo, Luciano Raposo de Almeida. "Equilibrio distante". Varia História 32 (2004): 144-175.

- "Revoltas, fiscalidade e identidade colonial na América portuguesa: Rio de Janeiro, Bahia e Minas Gerais, 1640-1761”. Tese de Doutorado, Universidade de São Paulo, 1996.

França, Eduardo D’Oliveira. Portugal na época da Restauração. São Paulo: HUCITEC, 1997. 
Freire, Felisbello. História da Cidade do Rio de Janeiro (1564-1808). Rio de Janeiro: Revista dos Tribunais, 1912.

Freitas, Gustavo. "A Companhia Geral do Comércio do Brasil [1649-1720]: subsídios para a História Econômica de Portugal e Brasil" Revista de História (1951): 307-328.

Gama, Maria Luísa Marques da. "O Conselho de Estado no Portugal Restaurado: teorização orgânica e o exercício do poder político na corte Brigantina (16401706)". Dissertação de Mestrado, Universidade de Lisboa, 2011.

Godinho, Vitorino Magalhães. Ensaios II: sobre a História de Portugal. Lisboa: Livraria Sá da Costa Editora, 1978.

_. "Portugal, as frotas do açúcar e as frotas do ouro". Revista Vértice 92,93,94. (1951): 69-88.

Loureiro, Marcello José Gomes. "Iustitiam Dare: a gestão da Monarquia pluricontinental. Conselhos superiores, pactos, articulações e o governo da monarquia pluricontinental portuguesa (1640-1668)". Tese de Doutorado, Universidade Federal do Rio de Janeiro; Ecole des Hautes Etudes em Sciences Sociales, 2014.

Mello, Evaldo Cabral de. O negócio do Brasil: Portugal, os Países Baixos e o Nordeste (1641-1669). São Paulo: Companhia das Letras, 2011.

Mendoça, Marcos Carneiro. O Marques de Pombal e o Brasil. São Paulo: Cia. Editora Nacional, 1960.

. Raizes da formação administrativa do Brasil. Rio de Janeiro, IHGB, 1972.

Mont Serrat, Pablo Oller. "O império português no Atlântico: poderio, ajuste e exploração (1640-1802)”. Tese de Doutorado em História, Universidade de São Paulo, 2013.

Puntoni, Pedro. “A Provedoria-mor: fiscalidade e poder no Brasil colonial”. O Brasil na monarquia Ibérica. Ana Paula Meniage et al. São Paulo: Alameda, 2014.

Ricupero, Rodrigo. "O exclusivo metropolitano no Brasil e os tratados diplomáticos de Portugal com a Inglaterra (1642-1661)”. Revista História 176 (2017): 1-33. 
Salvador, José Gonçalves. Os cristãos-novos e o comércio no Atlântico meridional. São Paulo: Pioneira/MEC, 1978.

Sampaio, Antônio Carlos Jucá de. Na encruzilhada do Império: hierarquias sociais e conjunturas econômicas no Rio de Janeiro (c.1650-c.1750). Rio de Janeiro: Arquivo Nacional, 2003.

Sanches, Marcos Guimarães. "Fiscalidade e fomento na colonização do Brasil: orientações e contradições". Anais. XVIII Simpósio Nacional de História, Londrina: ANPUH, 2005.

Silva, José Justino de Andrade. Colleção Chronológica da Legislação Portuguesa. Lisboa: Imprensa de J.J.A. Silva, 1854.

Sá, Helena Trindade de. "A Alfândega do Rio de Janeiro: da União Ibérica ao fim da Guerra da Restauração (ca.1580-ca.1668)”. Dissertação de Mestrado, Universidade Federal do Estado do Rio de Janeiro, 2016. 